\title{
The Effect of Job Dissatisfaction and Workplace Bullying on Turnover Intention: Organization Climate and Group Cohesion as Moderators
}

\author{
Iheanacho Emeka Nwobia ${ }^{1} \&$ Majeed Saad Aljohani ${ }^{1}$ \\ ${ }^{1}$ Graduate School of Business, Universiti Kebangsaan Malaysia, Selangor DarulEhsan, Malaysia \\ Correspondence: Iheanacho Emeka Nwobia, Graduate School of Business, Universiti Kebangsaan Malaysia, \\ Selangor DarulEhsan, Malaysia. E-mail: ihemeka@gmail.com
}

Received: June 17, 2016 Accepted: October 14, 2016 Online Published: May 29, 2017

doi:10.5539/ijms.v9n3p136 URL: http://doi.org/10.5539/ijms.v9n3p136

\begin{abstract}
There have been numerous studies on employee turnover intentions but very few have advanced on the notion of job dissatisfaction and workforce bullying from a contingent perspective. This paper conceptually examines how organizational climate and group cohesion impact on the domain relationships. We introduce a conceptual model to analyze potential consequences of employee turnover intentions. This is an important gap as the literature on turnover intentions has lagged conceptual developments. Several research propositions are presented to provide guidelines for further empirical inquiries, hence precedes our understanding of the area of research. The paper concludes by discussing practical and methodological implications for future research endeavors.
\end{abstract}

Keywords: employee turnover, job dissatisfaction, workforce bullying, moderating effects

\section{Introduction}

Turnover intention indicates an employee's perceived prospect of leaving an organization, or the willingness of an individual to permanently retire from the organization (Hossam, 2014). Turnover intention is a workplace phenomenon that must be restrained as much as possible for it involves impairments. Abbasi \& Hollman (2008) asserts that employee turnover intention is a critical affair, particularly within the scope of human resources management as it can be very costly for an organization. In other words, when an employee leaves an organization, the ability of the remaining employees to complete their duties will likely be affected. We, therefore opine that turnover should be adequately controlled in the workplace. The retention of high quality employees is more important today than ever before. Emerging trends like globalization, technological advancement, and knowledge, make it necessary for firms not only to acquire butto retain human capital (Hin Kin \& Tracey, 2000). The costs and consequences of turnover have necessitated the need to retain key employees for organizational success. In line with this, managers have implemented human resource policies and practices to adequately reduce avoidable and unwanted turnover (Fulmer, Gerhart, \& Scott, 2003; Hom, Roberson, \& Ellis, 2008; Kacman \& Andrews, 2006). In brief, more organizations are increasingly becoming aware of the fact that in order for the organization to grow, it is necessary to maintain the intellectual capital of its employees to thrive favorably.

There is an abundance of studies and empirical research, predominantly in advanced countries, that investigate the relationship between employee satisfaction and turnover intentions. The result of such study by Walim Rahman (2013), for example, showed that employees' turnover intention is highly related to their perception of the workplace and their satisfaction. Besides inadequacy and shortcomings in management, there are numerous factors that impact on employees' intention to leave their job or the organization. Some of the main reasonsfor employee turnover included is couraging employee attitude, organizational configuration, management deficiencies, excessive job demands, undesirable experience in the organization, and job dissatisfaction (Wali \& Zekeriya, 2013). Other causes include, underpayment, limited career growth, lack of job commitment, undue work stress, and poor management. Conversely, job enrichment, job stability (Luna-Arocas \& Camps, 2008), employee engagement (Macey \& Schneider, 2008), and managerial or supervisor support (Noe, 2005) have been shown to limit turnover intentions.

All these factors point to how an employee perceives the degree of work stress and hence the level of satisfaction. Work stress occurs when employees perceive an imbalance between their work requirements and their capability and resources to meet these requirements (Yeoh Sok, 2010). Workers who are satisfied with their organization 
are more committed towards the organization and they have limited intention to leave their jobs. Workplace bullying is another important element affecting employees' turnover intention. Workplace bullying is known to be one of the major issues faced by mostorganizations. Employers and management researchers are actively paying attention in ensuring effective dealing of bullying at the workplace. This is a crucial issue to tackle as bullying significantly diminishes employees' satisfaction and performance, and this can be observed through absenteeism and turnover intention in the workplace (Faheem, 2013).

The purpose of this article is to address these issues by introducing a conceptual model of the effects of job dissatisfaction and workplace bullyingon employees' turnover intention. It is important to note that organizational climate and group cohesion are two important variables that could impact the relationship between job dissatisfaction, workplace bullying, and employees' turnover intention. A more detailed discussion and literature will be provided in the following section. Several relevant research propositions are developedto provide some guidelines and insights for futureempirical studies.

\section{Conceptual Background and Propositions}

\subsection{Employee Turnover}

Employee's turnover is a major organizational challenge in business organizations today. The impact of turnover has adversely affected organizations nationally and globally. It has proven to be one of the most costly human resource challenges confronting many organizations (Dailey \& Kirk, 2001). Mobley's (2002) showed that turnover intention was the immediate predictor (antecedent) of the actual turnover in an organization. Mobley's work was based on the Theory of Reasoned Action (TRA), first proposed by Fishbein \& Ajzen et al. (2009). The theory of reasoned action is based on the fact that the attitudes and subjective norms of people will lead to behavioral intentions. This means that intentions precede actual behavior (Fishbein \& Ajzen, 1975).

Employee's turnover is not spontaneous but rather a gradual process of disengagement. It can take anywhere from a few days up to years. Younger and unskilled employees are more likely to have turnover intentions as reported in the study by Helga (2015). Unacceptable salaries and high stress levels are also likely antecedents of turnover intentions (Helga, 2015). The strongest precursor or antecedent to actual turnover is turnover intention (Moblev, Horber, \& Hollingsworth, 1978; Steal \& Ovale, 1984). Therefore, in order to reduce the actual turnover, it is highly necessary to deal with turnover intentions. It is a measure of whether a business or organization's employees plan to leave their positions or whether that organization plans to remove employees from their positions. In the intensively competitive world, turnover is a worrisome issue in the organization. The organizations strive to minimize as much as possible, their turnover ratio and thus save costs. This is because turnover involves costs, e.g., cost of replacement of departed workers. Turnover has both negative and positive effects on the organization, for example, when turnover occurs, management incurs heavy cost of replacement of the departed staff. And when workers leave an organization, the efficiency of remaining workers is adversely affected, Riley (2006).

There are voluntary and involuntary turnovers. Voluntary turnover is not initiated by the organizations, but are decided by the employees themselves. Involuntary turnovers are forced on the employees by the organizations. Involuntary turnover is largely influenced by employee's low performance. Poor commitment within the organization is one of the strongest antecedents of turnover intention. Studies on turnover prominently focus on voluntary turnover. (Youngbeom, 2013), employees with longer tenure are less likely to leave the organization. Turnover is higher for middle level jobs than for both highly specialized as well as lower level employees (Milliken \& Martins, 1996). Married employees do exhibit low turnover intentions, but having children at home leads to higher turnover especially for women (Barak et al., 2001).

\subsection{The Effect of Job Dissatisfaction on Turnover Intention}

Job dissatisfaction is an unpleasant or negative, stress-related emotional state resulting to a re-appraisal of one's job or job experiences (Locke, 1976). Job dissatisfaction has been observed to directly affect turnover intention (Mobley, 2002), especially among younger employees (Elizabeth \& Medina, 2012). Job satisfaction, the reverse of job dissatisfaction, has also been suggestedto inversely relate to turnover intention (Mobley, 1997). It refers to the employee's affective response to a job, based on the employee's comparison between his or her desired outcomes and the actual outcomes (Egan et al., 2004; Fang, Tsai, \& Wu, 2010). Job dissatisfaction can cause an employee to withdraw from the job via absenteeism, lateness to work, sick leave, request for transfer, and etc. Job satisfaction is the positive emotional response to a job situation that results in employee attaining what they want from their job (Vidal et al., 2007). This implies that job dissatisfaction the reverse, is positively related to turnover intention (Spector et al., 2007; Trevor, 2001; Irvine \& Evans, 1995). Job dissatisfaction wears down job performance and triggers off employees' low morale and job turnover intention. When the attitude of an 
employee towards his or her job is negative, we refer to it as job dissatisfaction.

When employees are not happy with their jobs, job dissatisfaction results. In 2012, a survey conducted by Right Management shows that $65 \%$ were found to be dissatisfied with their jobs. In a Mercer Study worldwide the same year, of 30,000 workers surveyed, $56 \%$ of the workers around the globe, wanted to leave their jobs. Turnover is a measure of whether a business or organization employees plan to leave their positions or whether the organization plans to remove these employees from their positions. Turnover can be either voluntary or involuntary. In the intensely competitive world, we think that turnover is a worrisome issue in the workplace. Organizations strive to minimize as much as possible, their turnover ratio and thus save costs. This derives from the fact that turnover incurs cost of replacement, recruitment etc. Turnover is of two types, voluntary and involuntary turnover. When the employer "fires" the employee, it is involuntary, but when the employee leaves the organization on his own, then it is described as voluntary turnover (Dess \& Shaw, 2001). Turnover has both negative and positive impact on the organization. When turnover occurs, management incurs heavy cost of replacement of the workers who left the organization. And when workers leave the workplace, the efficiency of the remaining staff is naturally and adversely affected (Riley, 2008). When the attitude of an employee towards his or her organization is negative, this is referred to as job dissatisfaction. In 2012, a survey conducted by Right Management showed that $65 \%$ were found to be dissatisfied with their jobs. In a Mercer Study worldwide, of 30,000 workers investigated, $56 \%$ of them, around the globe, wanted to leave their jobs. It is therefore obvious that dissatisfaction in the workplace makes workers less committed, and enhances turnover intention.

\subsection{Mobleyian Actual Turnover Stages}

Employee actual turnover is a serious workplace phenomenon. It is not an instantaneous, but a gradual deliberate process. According to Mobley (1982), this process is arguably, of seven steps, viz:

1) Job dissatisfaction provoking thoughts of turnover.

2) Evaluating the merits of looking for and getting a new job.

3) Considering the cost of actual turnover.

4) Actual search for a new job opening.

5) Evaluating the acceptability of a new job.

6) Making comparison between current and alternative job positions.

7) A strong intention to effect actual turnover, ie turnover intention, translates into actual turnover.

Mobley, clearly recognized these seven distinct stages, which generate actual turnover among employees in the workplace. This originates from job dissatisfaction, when an employee is not happy with his job for whatever reason. Certain merits to be gained from searching for a new job opening are considered. The opportunity cost of wanting to change the present job is given adequate consideration. Eventually, searching for alternative job and the rationale for so doing is also thought of cautiously. Then the reasonableness of actual turnover is arguably achieved via comparisons between the current job and alternative job openings, for "a bird at hand is worth two in the bush". At this point, the employee may decide on actual turnover, thus turnover intention eventually, gives birth to actual turnover. Therefore we unarguably hypothesize that:

\section{H1: Job dissatisfaction is positively related to turnover intention.}

\subsection{The Effect of Workplace Bullying on Turnover Intention}

Keashly \& Jagatic (2003) defined bullying as the interaction between organizational members that is characterized by repeated hostile, verbal and non-verbal behavior, often non-physical, directed at a person in such a way that the victim's sense of himself as an employee and as an individual is negatively affected. The practice, evil as it is, is characterized by repeated bullying behavior stretching over a long period of time. The phenomenon wears down its victims considerably (Einarsen \& Skogstad, 1996). Bullying is a source of severe stress in the workplace (Zapf, 2001). This takes the form of direct acts such as verbal abuse, accusations and public humiliation, but it can also be of a more subtle nature in the form of gossiping, spreading rumors and social exclusion (Einarsen, Hoel, \& Notelaers, 2009). Workplace bullying and harassment have been identified as the antecedent or precursor of job dissatisfaction (Frank, 2000) which in turn, is translated into turnover intention (Chen et al., 2011). It has also been suggested that, given equal levels of job dissatisfaction, turnover intention is very likely when job satisfaction is declining (Chen et al., 2011). It was also suggested by Zapf \& Gross (2011), that workplace bullying may trigger thoughts of escape behavior, leading the victims of bullying to consider quitting the job to free themselves from further emotional stress. Given this background, we are of the opinion that bullying behavior increases the stress level in the organization, and this correspondingly engenders 
turnover intention. Faheem Rasool \& Furah Arzu (2013), are also of the opinion that workplace bullying has a positive impact on intention to leave the workplace. According to Mobley (2001), turnover intention is the strongest antecedent of actual intention. We therefore opine that in an organization where bullying thrives, stress levels are driven up, and this naturally enhances turnover intention and eventually actual turnover. We would thus opine that workplace bullying engenders job dissatisfaction, and thus hypothesize that;

\section{H2: Bullying behavior is positively related to turnover intention.}

\subsection{The Moderating Effects of Organizational Climate}

Organizational climate is defined as the employee's perception oforganizational features, like decision making, norms, and established rules and regulations prevailing in the workplace including working conditions (Patricia $\&$ Elaine, 2010). The culture of an organization represents organizational climate (Silvert Shorne, 2011). Organizational culture refers to the values, beliefs, and principles underpinning an organization's management structure as well as the customs and conduct that reinforce those principles (Adkin \& Coldwell, 2004). It is the established norms of behavior and shared ideals within the workplace. Organizational culture indirectly affects job satisfaction, thus it is plausible and reasonable to say that organizational climate is related to turnover intention. This reasonably implies that organizational climate influences turnover intention as a moderator. While some researchers may not allude to its strong relationship with turnover intention, we believe that it plays asignificant role as a moderator to turnover intention.

Organizational Climate concept was first developed in the 1930s by a social scientist, Kurt Lewin who conceptualized it as a particular social process involving the influence of a work setting on organizational members who are in subordinate power position. He also described it as an atmosphere that workers perceive in the organization as created by practices and procedures that staff observe in the workplace which govern their conduct and performance.

According to Lencioni (2009), organizational clarity is a dimension of organizational climate, which implies knowledge of the "personality" of the company, its existence, and the purpose the company serves. Organizational clarity is necessary for the development of the company's goals, strategies, mission, values and vision. The latter is the "heart" of the company. The "heart" of the company portrays its past and the future. From the foregoing, when most workers understand the vision, goals and expressed purpose of the organization, work can be delegated more effectively, employees feel more empowered and exhibit more confidence and commitment. Consequently, organizational clarity engenders a healthy organizational climate that promotes a sense of belonging of the employees. Given this backdrop, we opine that organizational climate accentuates the relationship between between turnover intention and job dissatisfaction.

One of the surest ways for an organization to fail is by tolerating bullying in the workplace. Severe stress in the workplace resulting from work-related or environmentally-related issues, can generate stress which in turn triggers off bullying behavior on the part of employees. Bullying results, when some worker in a subordinate position becomes persistently and emotionally traumatized and stressed up in the workplace. The situation aligns with Berkowitz's Frustration-Aggression Theory (1989). This theory associates bullying behavior with severe stress in the workplace. A stressful work environment can lead to aggression being meted out by one group of employees against another. Employees who cannot cope effectively with stress, may violate existing work-related expectations and norms in the workplace. This can cause other workers to develop a negative attitude towards them. Such victims feel deeply demoralized at the workplace. Such cases may trigger off turnover tendencies. Thus, bullying could generate turnover behavior (Berthelson, 2011; Edeian, 1991; Lee, 1999; Holtom, 2005). Stressful experiences at the workplace may induce negative emotions on employees, which in turn, may lead them to engage in aggressive behavior towards others (Hang, Skog Stad, \& Einersen, 2007). Employees exposed to bullying behavior, develop interpersonal conflicts, role conflicts and role ambiguity. All these will eventually precipitate bullying behavior among the workers. The victims of these behaviors suffer consequences and the organization is worse off in terms of employee turnover and turnover costs (Bowling \& Beehr, 2006). Exposure to workplace bullying, coupled with an unpleasant organizational climate would have detrimental consequences on affected individuals (Aquino \& Thau, 2009; Bowling \& Beehr, 2006). Based on this backdrop, we therefore hypothesize the following relationship:

H3: The positive relationship between job dissatisfaction and turnover intention isenhanced (stronger), particularly among employees who work underdiscouragingorganizational climate.

H4: The positive relationship between workplace bullying and turnover intention isenhanced (stronger), particularly among employees who work underdiscouraging organizational climate. 


\subsection{The Moderating Effects of Group Cohesion}

Group cohesion refers to a dynamic process reflected in the tendency for a group to stick together and remain united in the pursuit of certain objectives (Carron et al., 1987). The degree to which members of a group are attached to one another, and have the desire to remain a part of the group, constitutes group cohesion. Group cohesion is the sum of all factors causing members of a group to stay in the group or be attracted to the group. Raymond Friedman Holton (2002), Group cohesion helps companies to control turnover intention and also Griffeth (2000), group cohesion impacts directly on turnover intention. It moderates the detrimental effects of environmental constraints on organizational behavior and thus produces better cohesiveness, andstronger organizational commitment and results (Evans, 2001; Langfred et al., 1998). Williams \& Skinner (2003) posited that there is a negative correlation between job satisfaction and turnover intention, and therefore it is logical to assert that uncooperative group cohesion will further reinforce the job dissatisfaction-turnover relationship. Operationalizing group cohesion is somewhat problematic. Mudrack (2001) argued that achieving a reliable value for group cohesion requires giving the construct a multidimensional review. However, these researchers agreed that attraction is one of the antecedents of group cohesion. This construct is important because we are compelled to believe that group cohesion accentuates the relationship between job dissatisfaction and turnover intention. The term cohesion originated from Cohaesus, a Latin word meaning binding intimately and closely; it is a dynamic process in which team members work very closely to accomplish objectives (Chi Dambaram \& Jones, 2006). If team members or employees do not experience a sufficient level of cohesion, then there is a strong possibility that members will leave the organization (O'Reilly et al., 2002). This clearly shows that cohesive strength builds up immense tendency to stay back in the workplace. Therefore group cohesion influences stay back tendency and is somewhat inversely related to turnover tendencies. This is a plausible assertion. Based on this view, uncooperative group cohesion should enhance the impact of workplace bullying on employee turnover intentions. We therefore hypothesize the following:

H5: The positive relationship between job dissatisfaction and turnover intention is enhanced (stronger), particularlyamong employees who experienceuncooperative group cohesion.

H6: The positive relationship between workplace bullying and turnover intention is enhanced (stronger), particularly among employees who experienceuncooperative group cohesion.

\section{Methodology}

In order to investigate the hypotheses of this study, future researchers should choose a research approach based on deductive reasoning methods (Saunders, 2001), to suit the proposed model framework and the hypotheses. The sample for this study which should be obtained from an established sample frame and a sample of at least 200 employees, is recommended for adequate investigation. The researcher(s) is/are then advised to distribute a survey questionnaire to employees at their workplaces via person-administered methods. This measure is taken to ensure that the respondents' experiences about job dissatisfaction, and the effect of job dissatisfaction on turnover intention will be explored. A quantitative analysis, e.g., regression processs, would then be applied to examine the relationship between the constructs, so as to validate the hypotheses.

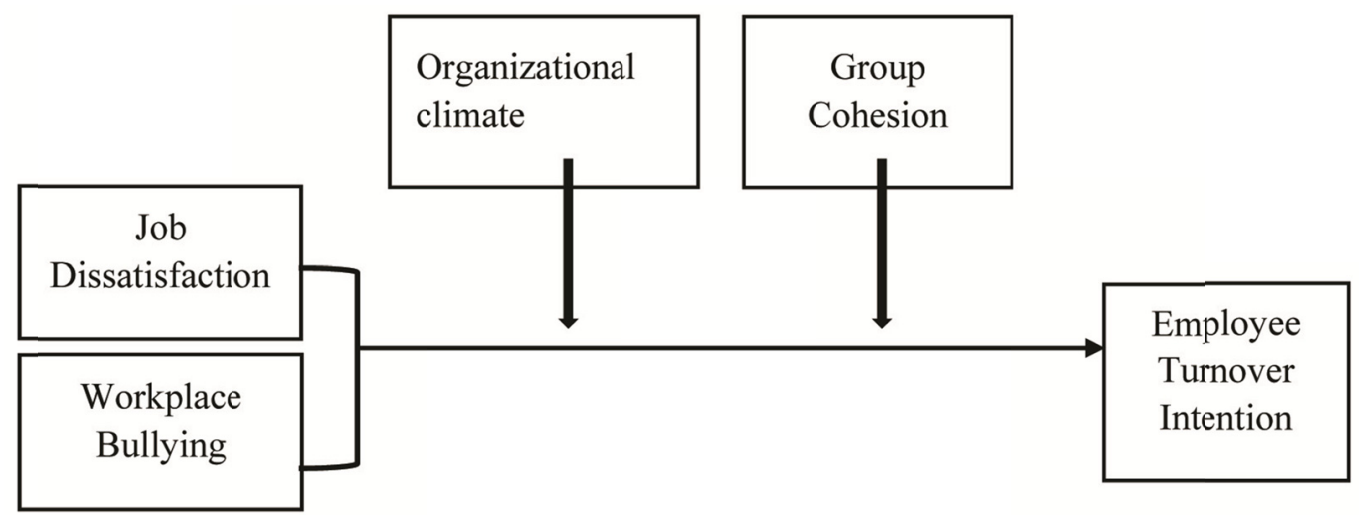

Figure 1. A conceptual framework 


\section{Discussion}

This study aims to investigate the relationship between job dissatisfaction and workplace bullying and turnover intention of employees. Moreover, the study examines the adverse effects of organizational climate and group cohesion as moderators. It will appraise and develop appropriate organizational climate for workers in an organization. This is necessary in supplying Management with information as well as data that can be utilized to outline suitable strategies to enhance employee loyalty. Therefore the findings of this study should be useful in the workplace in the areas of employee satisfaction, job loyalty, and service quality in both government institutions and service industries.

Examination of the literature indicates that there is a gap in determining the impact of organizational climate and group cohesion as moderators in the relationship between job dissatisfaction, workplace bullying and turnover intention in organizations. Information is needed to deliver knowledge to organizations' managers in meeting individuals' needs that can positively influence job satisfaction and performance at work. This study attempts to fill this gap by understanding the behavior of employees in organizations, hence to assist firms in managing employees in order that they remain loyal in the organization. This conceptual paper should be seen as an initial attempt to emphasize the role of managers in managing conflicts and the need to generate different types of motivations thatcan influence employee behavior as well as stay back intentionsin the workplace. Appropriate strategies are required to be put in place to satisfy individualneeds in the organization. This paperwould enable empirical testing to follow suit, and will potentially provide critical information to assist decision makers and employees to understand their commitments and obligations to ensure high-quality performance in the organization, and to drastically reduce actual and turnover intentions.

\section{Conclusion}

In order to investigate the hypotheses of this study, future researchers should choose a research approach based on deductive reasoning theories (Saunders et al., 2007) to suit the proposed model framework and hypotheses. The sample for this study should be obtained from established sample frame and a sample of at least 200 employees,is recommended for adequate investigation. The researcher(s) is/are then advised to distribute a survey questionnaire to employees at their workplaces via a person-administered method. This measure is taken to ensure that the respondents' experiences about job dissatisfaction and the effect of job dissatisfaction will be brought to bear on turnover intention. Aquantitative analysis (e.g., regression analysis) would then be applied to examine the relationship between variables, so as to validate the hypotheses. In conclusion, while this work is restricted by its exploratory formation, it offers an opening for empirical investigation into the true relationship between employee job dissatisfaction and workplace bullying on turnover intention, and the moderating constructs of organizational climate and employee' group cohesion.

\section{References}

Abbas, S. M., \& Hollman, K. W. (2008). Turnover turned over: An expanded and positive perspective. Academy of Management Review, 41(23).

Adkin \& Coldwell. (2014). Turnover: The real bottom line. Public Personnel Management, 2(3).

Ali, H., Arslan, R., \& Abdul, R. K. (2013). A longitudinal Study of the Moderating role of extraversion and Group Cohesion. JAP, 91(31).

Aquino \& Thau. (2006). Job Satisfaction \& Turnover Among Nurses. JAP, 33(14).

Barak, E. M., \& Egan. (2004). Organizational Culture \& Job Satisfaction. Journal of Busi-Ness and Industrial Marketing, 18(7).

Bethelson \& Holton. (2005). Impact of Job Satisfaction Components on turnover Intention. IJNS, 44(14).

Bethelson \& Edeian. (2011). Jos Dissatisfaction \& Turnover Intention: The Moderating Effects of Organizational Commitment. JSP, 139(45).

Chen, Quine, \& Mathesien. (2003). Employee Turnover: A meta-analysis \& review for research. Academy of Management Review, 11(51).

Chi Dambaran \& Jones. (2006). Organizational Commitment and Job Satisfaction in the Work-Place. JOP, 135(26).

Chi Dambaran \& O'Reilly. (2006). Workplace Bullying and Turnover Intention: The Moderating Effects of Organizational Commitment. Information Management \& Business Review, 5(41).

Caron \& Evans. (2001). Consequences of Bullying: An increasing challenge for the workplace. Canadian 
Journal of School Psychology, 27(11).

Dailey \& Kirk. (2001). Test of Mediated Turnover, highlighting the moderating roles of reward contingencies. JAP, 30(21).

Dess \& Shaw. (2001). The Role of Perceived Organizational Support in the Turnover Process. Journal of Marketing, 29(18).

Egan \& Ya Fung. (2004). The Relative Influence of Organizational Commitment and Job Satisfaction on Service delivery. Journal of Service Marketing, 18(7).

Einarsen, Hoel, \& Notelaers. (2009). Job Satisfaction and Turnover Intention. Nurses \& Health Sciences Journal, $17(9)$.

Elaine, W. S., Silverthorne, \& Adkin. (2004). A Model of High Performance Practices and Turnover Intentions. Journal of Personnel Review, 37(1).

Elizabeth, M. (2012). Contention, Causes and Consequences of Job Insecurity. Academy of Management Journal, $5(27)$.

Evans \& Longfred. (2001). Integrating Justice Constructs into the turnover Process. AMJ, 5(27).

Faheem. (2013). Job Satisfaction \& Dissatisfaction. JNA, 31(14).

Faheem, Rasool, \& Arzu, E. (2013). Turnover Intention and Voluntary Turnover: The Moderating roles of Locus control and Group Cohesion. JAP, 90(8).

Ferris \& Zapf. (2009). Bullying: Challenges and Opportunities for a research. Scandinavian Journal of Psychology, 50(24).

Fishbein \& Ajzen. (2005). Leader Member and Turnover Intention. Management Research Review, 37(2).

Fulmer, Gerhart, \& Scott. (2003). The Relationship Among Organizational Context, Payment Diversion and managerial turnover. Academy of Management Journal, 45(14).

Griffeth (2000). Human Resources Management: Gaining a Competitive Advantage (5th ed.). New York: McGraw-Hill.

Hang, Skogstad, \& Einersen. (2007). Employee Development and turnover Intention: Theory Validation. European Journal Training \& Development, 37(6).

Helga. (2015). Unemployment, dissatisfaction and employee turnover. JAP, 72(41).

Hinkin \& Tracey. (2000). The Role of the change in the relationship between Job commitment and turnover. JAP, 92(42).

Hossam, M., \& Abu, E. (2014). An exploratory study on turnover Intention Among private Sector employees. IJBM, 5(8).

Jagatic, Behr, \& Coldwell. (2004). Reducing Voluntary Turnover via Selection. JAP, 90(12).

Kacman \& Andrews. (2006). Locus of Control as Potential moderator of the turnover process. JOP, 60(2).

Kacman, A., \& Dailey, K. (2002). Voluntary Turnover, Social capital and Organizational Commitment. Academy of Managenent Journal, 26(45).

Keashly \& Jagatic. (2002). Intermediate Linkages In the relationship between Job satisfaction and employee turnover. JAP, 62(38).

Langfred \& Mudrack. (1999). Why People Stay: Using Job embeddedness to Predict Voluntary Turnover. AOMJ, 44(12).

Lencioni. (2009). The Consequencies of Turnover Intention. Journal of Occupational Behaviour, 2(11).

Lim \& Burkim. (2010). Organizational Commitment, Job Satisfaction and Efforts in the service environment. JOP, 135(2).

Locke. (1999). Employee Dissatisfaction and Turnover Crisis in the Malaysian Hospitality Industry. International Journal of Business Management, 8(5).

Luna-Arocas \& Camps. (2008). Executive Turnover Revisited from an efficiency wage perspective. Journal of American Academy of Management, 2(1).

Macey \& Schneider. (2007). Psychology of Work. San Francisco: McGraw-Hill Co, Inc. 
Mobler, H., \& Steal. (1999). Reducing Turnover In the Hospitality Industry: An Overview of recruitment, selection, and retention. IJHRM, 11(1).

Milliken \& Martins. (2001). Linking Development Practices toTurnover: Perceived Organi-zational Support as Mediator. JBPA, 2(11).

Mobley. (1997). How Job Dissatisfaction Leads to Employee Turnover. Journal of Business Psychology, 2(3).

Mobler, Horber, \& Hollingworth. (2000). Assessment of Causes of Turnover In Hospitality Industry In Kenya. International Journal of Business and Social Sciences, 3(15).

Mudrack. (2001). Job Burnout. Journal of Annual Review of Psychology, 51(2).

Noe. (2005). Job Dissatisfaction and Turnover Intention AmongSkilled Personnels. JAP, 39(17).

O’Reilly. (2006). Employee Turnover, Causes, Consequences and Control. JAM, 70(21).

Raymond Friedman Holton. (2002). Work Stress and Customer Service Delivery. Journal of Services Marketing, 13(3).

Riley. (2006). A Critical Survey of Employee Turnover. African Journal of Business Management, 4(19).

Saunders. (2009). Employee Turnover, Individual and Organizational Analyses. Journal of Research In Personnel Management, 26(9).

Silvertshone. (2011). Voluntary Turnover and Alternative Job Opportunities. JAP, 75(14).

Spector \& Irvine. (2007). A meta-analysis of Employee Turnover. JAP, 77(18).

Vidal. (2007). Employee Turnover. Academy of Management Journal, 19(9).

Wali \& Zekeriya. (2013). Effects of Family Structure on Organizational Commitment and Turnover Intention. Academy of Management Journal, 42(12).

Wali \& Rahman. (2013). The Unfolding Model of Voluntary Employee Turnover. JAM, 39(16).

Williaws \& Skinner. (2003). Intermediate Linkages In the relationship between Job dissatisfaction and employee turnover process. JAP, 62(23).

Yantang, Tsai, \& Wang-Wu. (2010). Employee Turnover and post-decision process. Journal of Research in Organizational Behaviour, 3(12).

Yeoh Sok. (2010). A multivariate Analysis of the determinants of Job Turnover. JAP, 67(13).

Yeoh Sok \& Osman, S. (2013). Understanding Voluntary Turnover. Academy of Management Journal, 51(4).

Youngbeom. (2013). Motivational Forces of Voluntary Turnover: Implications for Research. Journal of Management, 30(5).

Zapf. (2001). Bullying Behaviour and Voluntary Turnover. Journal of Applied Psychology, 20(18).

Zapf \& Gross. (2011). The Effects of Workplace Bullying Behaviour on Employee Turnover Intention. Annual Review of Psychology, 41(17).

\section{Copyrights}

Copyright for this article is retained by the author, with first publication rights granted to the journal.

This is an open-access article distributed under the terms and conditions of the Creative Commons Attribution license (http://creativecommons.org/licenses/by/4.0/). 